\title{
Influence of postoperative pain and use of NSAID on heart rate variability of dairy cows
}

\section{Frondelius, Lilli}

2018-02

Frondelius , L , Hietaoja , J K , Pastell , M , Hänninen , L T , Anttila , P \& Mononen , J 2018 ,

' Influence of postoperative pain and use of NSAID on heart rate variability of dairy cows ', pÿJournal of Dairy Research , vol. 85 , no. 1 , pp. 2729 . https://doi.org/10.1017/S0022029917000760

http://hdl.handle.net/10138/312764

https://doi.org/10.1017/S0022029917000760

cc_by_nc_nd

acceptedVersion

Downloaded from Helda, University of Helsinki institutional repository.

This is an electronic reprint of the original article.

This reprint may differ from the original in pagination and typographic detail.

Please cite the original version. 
Influence of postoperative pain and use of NSAID on heart rate variability of dairy cows

1 Lilli Frondelius ${ }^{1}$, Juha Hietaoja ${ }^{2}$, Matti Pastell ${ }^{1}$, Laura Hänninen ${ }^{3}$, Paula Anttila ${ }^{4}$, Jaakko Mononen ${ }^{1}$

$2{ }^{1}$ Natural Resources Institute Finland (Luke), Green technology, Halolantie 31 A, 71750 Maaninka,

3 Finland

$4{ }^{2}$ University of Helsinki, Faculty of Agriculture and Forestry, Department of Agricultural Sciences,

5 P.O Box 28, 00014 University of Helsinki, Finland

$6{ }^{3}$ University of Helsinki, Faculty of Veterinary Medicine, Department of Production Animal

7 Medicine, P.O. Box 57, 00014 University of Helsinki, Finland

$8 \quad{ }^{4}$ Maalaiseläinlääkäri Anttila, Halolantie 27, 71750 Maaninka, Finland

9 correspondent author: Lilli Frondelius, lilli.frondelius@luke.fi

10

11 Summary

12 This Research communication describes the effect of post-operative pain and NSAID treatment on

13 heart rate variability (HRV) of dairy cows. Postoperative pain in farm animals is often left 14 untreated. HRV could be a promising tool for pain assessment in animals. The aim of this study was to assess if postoperative state after subcutaneous surgery and NSAID treatment affect HRV in dairy cows. Nine cows were inserted with an implantable electrocardiograph logger. Cows were 17 divided into the NSAID treatment group and the control group. The cows in the NSAID group had higher HRV than the control group, indicating a higher sympathetic activity in control animals, most likely due to untreated post-operative pain. Besides the ethical need for treating pain in production animals, ongoing pain has an adverse effect on animal productivity. Thus post-

21 operative pain alleviation is recommended.

Key words: Dairy cattle, Heart rate variability, Pain, Nonsteroidal anti-inflammatory drug 

properly, but treatment for postoperative pain is seldom given (Walker et al. 2011). Behaviours, such as restlessness, foot stamping and changes in lying behaviour, are used for assessing farm animal pain, but also physiological parameters, such as stress hormones, are assessed (ViñuelaFernández et al. 2007). However, both behavioural and traditional physiological approaches have their limitations in sensitivity and reliability and new methods for effective pain assessment are needed. Heart rate variability (HRV) can be used as an indicator of the sympathovagal balance of assessment in farm animals (calves: Stewart et al. 2008 and 2010; ewes: Stubsjøen et al. 2009). However, results of HRV measurements are inconsistent: pain has been shown either to increase 
The study was conducted at the Natural Resources Institute Finland research barn in Maaninka,

Finland. The experimental animals were four pregnant heifers and seven dry cows (six HolsteinFriesian and five Ayrshire). The animals were tethered in peat-bedded rubber-matted tie stalls (width $120 \mathrm{~cm}$, length $180 \mathrm{~cm}$ ). They were fed daily with $0.3 \mathrm{~kg}$ of barley concentrate (energy content 13.2 MJ ME/kgDM), 0.2 kg commercial mineral for dry cows (Tunnu-Namino, Hankkija Oy, Finland), and $32 \mathrm{~kg}$ (multiparous cows) or $36 \mathrm{~kg}$ (heifers) grass silage (10.5 MJ ME/kgDM). cow

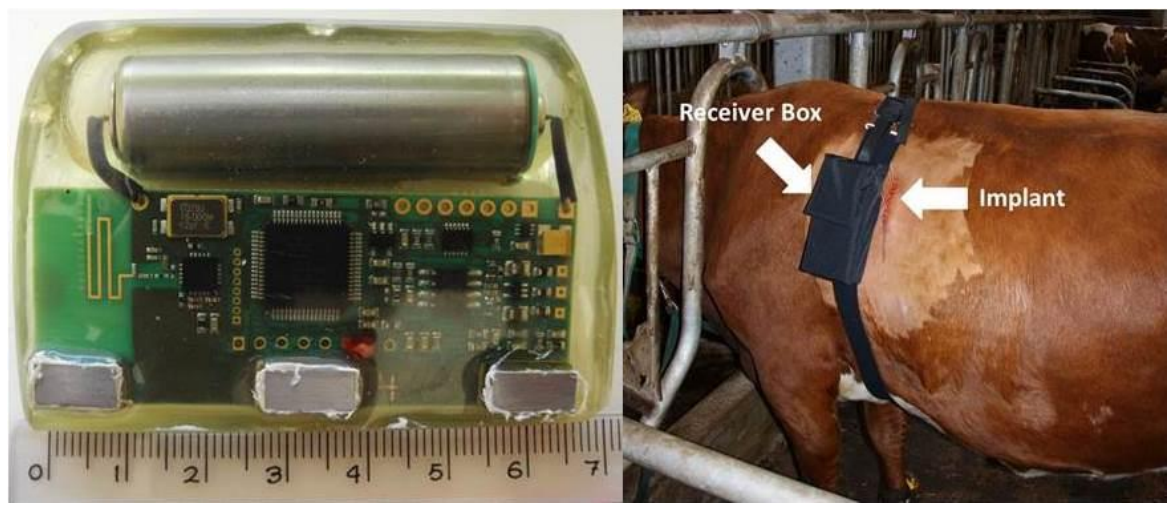


The animals were operated about one month ( \pm 3 days) prior to the expected parturition date under sedation $(0.018 \mathrm{mg} / \mathrm{kg}$ xylazine hydrochloride $20 \mathrm{mg} / \mathrm{ml}$ intravenously) and local anesthesia (20 - $35 \mathrm{ml}$ lidocaine hydrochloride $20 \mathrm{mg} / \mathrm{ml}$ subcutaneously). The animals received three-day antibiotic treatment $(20000 \mathrm{lU} / \mathrm{kg}$ penicillin benzathine and penicillin procaine $300000 \mathrm{lU} / \mathrm{ml}$ intramuscularly) post-operatively.

Heifers and cows were randomly divided into the treatment ( 1 heifer +5 cows) and the control ( 3 heifers +2 cows) groups. On the operation day the treatment group received intravenous NSAID treatment (3 mg/kg ketoprofen $100 \mathrm{mg} / \mathrm{ml}$ ). An oral NSAID treatment (4 mg/kg ketoprofen 160 $\mathrm{mg} / \mathrm{g}$ ) mixed in a small amount of concentrates continued for the four consecutive days (days 1 4) after the operation day. The control group did not receive any NSAID treatment, but a small amount of concentrates as a control treatment on the days $1-4$. An oral ketoprofen has been effectively used previously e.g. with acute mastitis in dairy cows (Banting et al. 2008).

ECG of the experimental animals was measured and behaviour video recorded during days $1-4$ using cameras (Axis Q1755-E and Axis 215) positioned to face downwards to the tie-stalls. The body and head postures and rumination of the animals were recorded continuously twice daily, $05.00-07.00$ and $22.00-24.00$. Because the posture of the animal affects the HRV (Frondelius et al. 2015) only the ECG data from continuous lying periods (sternal recumbency while head up) from animals not ruminating were used for the HRV analysis. ECG data from these periods were visually inspected and good quality five-minute segments were selected for further analysis. Data from two control group animals were discarded because of unreadable ECG data due to malfunctioning of the implants. 
The ECG data were interpolated to $500 \mathrm{~Hz}$ using a geometric interpolation method (Tiusanen et al. 2015) and the location of the $S$ wave (Tiusanen \& Pastell 2016) was used to analyze the normal-tonormal (NN) intervals. We calculated heart rate (HR), the standard deviation of NN intervals (SDNN), root mean square of successive NN interval differences (RMSSD) and pNN50 (Task Force 1996).

HRV data from the nine animals (treatment $n=6$, control $n=3$ ) were used for the analysis including mean daily values of HRV parameters from 94 five-minute segments; 58 segments from the treatment group and 36 segments from the control group, $10.4 \pm 5.87$ (mean \pm SD) segments per cow. Linear mixed models were fitted to determine the effect of independent variables treatment (control vs NSAID), time from the procedure (days $1-4$ ) and the interaction between these two - on HRV parameters (dependent variables) using compound symmetry as a covariance structure and cow as a random effect. The statistical analyses were made with SAS for Windows version 9.2 through SAS Enterprise Guide version 4.3 (SAS Institute Inc., Cary, NC, USA).

\section{Results and discussion}

The cows in the treatment group had higher SDNN and tended to have higher RMSSD values than the animals in the placebo group (Table 1). There were no differences in HR and pNN50 between two groups. The day did not have any effect on HRV values and there was no interaction between the treatment and the day.

The results indicate that NSAID affects the postoperative HRV of adult dairy cows that had undergone subcutaneous implantation. The control group had a lower vagal tone and a stronger sympathetically controlled response (von Borell et al. 2007) to the postoperative state, most likely 
due to untreated pain. Ketoprofen might have also mitigated the inflammatory reaction towards the implant due to NSAIDs anti-inflammatory and anti-pyretic effects (Donalisio et al. 2012).

We did not observe any effect of NSAID treatment on long-term HR. This result is similar to Raekallio et al (1997), who studied horses for 72 hours after arthroscopic surgery. Generally higher sympathetic activity is connected to increase in HR (Von Borell et al. 2007) and lack of pain medication increases HR (Stewart et al. 2008, Stubsjøen et al. 2009). In these studies, however, HR was measured only during the painful procedure or few hours after it. This difference in methods may partly explain lack of difference in HR in our study, since we started measurements of cardiac responses one day after the surgery and measured it throughout the whole four-day postoperative treatment. However, it is also possible that ketoprofen was not a potent enough NSAID to cause differences in HR, as in the study by Newby et al. (2014).

With this small number of the animals, our experiment should be regarded as a case study. However, linked with other results, we suggest that HRV may be a sensitive measure for assessing pain in production animals. Stubsjøen et al. (2009), who also used a limited number of animals in their study, found that moderate pain in sheep had an effect on HRV.

This study shows that dairy cows are subjected to postoperative pain even after small-scale subcutaneous surgery. In production animals postoperative pain is often neglected (Walker et al. 2011). Besides the ethical need for treating pain, ongoing pain may also have an adverse effect on animal productivity, affecting their growth and immune functions (Anil et al. 2005). Thus pain alleviation during and after painful procedures is beneficial for the animal, the producer and the consumer. 
The authors wish to thank the staff of Luke Maaninka research barn for technical assistance and

Vetcare Oy for providing pharmaceuticals used in the study. This study was part of a project

funded by the Maaseudun kehittämisrahasto under the Finnish Ministry of Agriculture and

Fisheries (grant number 2872/502/2008).

References

Anil L, Anil SS \& Deen J 2005 Pain detection and amelioration in animals on the farm: Issues and options. Journal of Applied Animal Welfare Science 8261 - 278

Banting A, Banting S, Heinonen K \& Mustonen K 2008 Efficacy of oral and parenteral ketoprofen in lactating cows with endotoxin-induced acute mastitis. Veterinary Record $163506-509$

Bjarnason Á, Vuorela T, Verho J, Riistama J, Vanhala J, Lekkala J \& Hyttinen J 2013 Implantable measurement system for dairy-cattle monitoring with long recording time. Advances in Science and Technology $8533-38$

Donalisio C, Barbero R, Cuniberti B, Vercelli C, Casalone M, Re G 2012 Effects of flunixin meglumine and ketoprofen on mediator production in ex vivo and in vitro models of inflammation in healthy dairy cows. Journal of Veterinary Pharmacology and Therapeutics $36130-139$

Frondelius L, Järvenranta K, Koponen T \& Mononen J 2015 The effects of body posture and temperament on heart rate variability in dairy cows. Physiology \& Behavior $139437-441$ 
Newby NC, Tucker CB, Pearl DL, LeBlanc SJ, Leslie KE, von Keyserlingk MAG, Duffield TF 2014 An

investigation of the effects of ketoprofen following rumen fistulation surgery in lactating dairy

cows. The Canadian Veterinary Journal 55442 - 448

Raekallio M, Taylor PM \& Bennett RC 1997 Preliminary investigations of pain and analgesia assessment in horses administered phenylbutazone or placebo after arthroscopic surgery. Veterinary Surgery $26150-155$

Stewart M, Stafford KJ, Dowling SK, Scaefer AL \& Webster JR 2008 Eye temperature and heart rate variability of calves disbudded with or without local anaesthetic. Physiology \& Behaviour 93 $789-797$

Stewart M, Verkert GA, Stafford KJ, Schaefer AL \& Webster JR 2010 Noninvasive assessment of autonomic activity for evaluation of pain in calves, using surgical castration as a mode. Journal of Dairy Science $963602-3609$

\section{Stubsjøen SM, Flø AS, Moe RO, Janczak AM, Skjerve E, Valle PS \& Zanella AJ 2009 Exploring non-} invasive methods to assess pain in sheep. Physiology \& Behaviour $98640-648$

Task Force of The European Society of Cardiology, North American Society of Pacing and Electrophysiology 1996 Heart rate variability - Standards of measurement, physiological interpretation, and clinical use. Circulation $931043-1065$ 
Tiusanen J, Hautala MI, Ternman EM \& Pastell ME 2015 Geometrical method for interpolating S-

using a microcontroller. Agricultural Engineering International: CIGR Journal 18411 - 418

Tiusanen J \& Pastell M 2016 Simple online algorithm for detecting cow's ECG beat-to-beat interval

Viñuela-Fernández I, Jones E, Welsh EM \& Fleetwood-Walker SM 2007 Pain mechanism and their implication for the management of pain in farm and companion animals. The Veterinary Journal

$174227-239$

Von Borell E, Langbein J, Deprés G, Hansen S, Leterrier C, Marchant-Forde J, Marchand-Forde R, Minero M, Mohr E, Prunier A, Valance D \& Veissier I 2007 Heart rate variability as a measure of autonomic regulation of cardiac activity for assessing stress and welfare in farm animals - A review. Physiology \& Behavior $92293-316$

Walker KA, Duffield TF \& Weary DM 2011 Identifying and preventing pain during and after surgery in farm animals. Applied Animal Behaviour Science 135259 - 265

Table 1. Comparison of the linear mixed model estimates of heart rate variability (HRV) variables ( mean \pm SEM) between NSAID (cows $n=6$; analyzed 5 -minute HRV segments $n=58$ ) and placebo groups (cows $n=3$; analyzed 5-minute HRV segments $n=36$ ).

\begin{tabular}{l|ccc} 
& NSAID & Placebo & P \\
\hline HR & $61.0 \pm 3.84$ & $61.8 \pm 5.55$ & ns
\end{tabular}




\begin{tabular}{l|lcc} 
SDNN & $56.1 \pm 2.16$ & $45.6 \pm 3.39$ & $<0.05$ \\
RMSSD & $60.8 \pm 1.96$ & $54.3 \pm 3.09$ & $<0.1$ \\
pNN50 & $6.21 \pm 1.58$ & $4.96 \pm 2.40$ & ns
\end{tabular}

